\title{
ARTESANATO COM FIBRA DE BANANEIRA: UMA EXPERIÊNCIA NO VALE DO RIBEIRA, SP
}

\author{
*Maria Elisa de Paula Eduardo Garavello, **Silvia Maria Guerra Molina, \\ ***Márcia Regina da Silva, ****Eneida Elisa Mello Costa
}

\section{RESUMO}

O presente trabalho relata a experiência obtida com o desenvolvimento do Projeto de Aproveitamento de Resíduos da Bananicultura, no Vale do Ribeira, SP, na área artesanal, e discute a importância da interdisciplinaridade na integração ensino, pesquisa e extensão. Tal Projeto proporcionou a vivência de questões fundamentais que se colocam para academia quando se trata da geração de conhecimento científico visando a sua disponibilização para a inclusão social e a cidadania. Permitiu discutir a necessidade da construção de uma Universidade, que aproxime a sociedade dos limites da academia, e contribuir, portanto, para a formação de conhecimentos que considerem as experiências sociais e a integração de diferentes áreas do saber.

Palavras-chave: Artesanato. Extensão. Cidadania.

\section{ABSTRACT}

The present work reports the experience in the Project of Exploitation of Residues of the Growth of Banana, in the Ribeira River Valley, SP; in the craftsmanship area and accosts the importance of interdisciplinarity when it comes to integrate education, research and extension. This Project provided the discussion of basic questions, that present themselves to the academy, concerning the generation of scientific knowledge with educative ends, aiming at the social inclusion and the citizenship. It was allowed the discussion about the necessity of the construction of a university which would bring the society closer to the academic limits, contributing, therefore, for the formation of knowledge that considers the social experiences and the integration of different areas of knowing.

Key words: Craftsmanship. Extension. Gitizenship.

\footnotetext{
* Professora Doutora do Departamento de Economia, Administração e Sociologia da ESALQ-USP, R. Pádua Dias, II - LES ESALQ-USP - Piracicaba-SP - I34I8-900 - e-mail: mepegara@esalq.usp.br ** Professora Doutora do Departamento de Genética da ESALQ-USP *** Doutoranda do Programa de Pós-graduação em Ecologia de Agroecossistemas da ESALQ-USP **** Professora Doutora Aposentada do Departamento de Economia, Administração e Sociologia da ESALQ-USP
} 


\section{INTRODUÇÃO}

Nas atuais discussões relativas ao papel da universidade, um ponto recorrente de análise é a urgência de uma maior aproximação desta com a sociedade, prioritariamente com os setores mais desfavorecidos. Nessa direção, a extensão universitária tem um papel importante a cumprir, como intermediária na ampliação do vínculo entre ensino e pesquisa, na difusão dos conhecimentos desenvolvidos na academia, e ao mesmo tempo contribuindo para uma ação recíproca de troca de conhecimentos.

De acordo com Santos (2003), "a legitimidade da Universidade só será cumprida quando as atividades de extensão se aprofundarem tanto que desapareçam enquanto tais e passem a fazer parte integrante das atividades de investigação e ensino".

O presente trabalho relata uma experiência de pesquisa e extensão integradas, na direção mencionada, desenvolvida a partir do Projeto de Aproveitamento de Resíduos da Bananicultura, no Vale do Ribeira, SP, na área artesanal.

\section{HISTÓRICO DO PROJETO}

O artesanato com fibra de bananeira foi desenvolvido pela Escola Superior de Agricultura Luiz de Queiroz da Universidade de São Paulo (ESALQUSP), como parte integrante daquele Projeto, a partir de I99I. O mesmo foi financiado pela Secretaria de Giência, Tecnologia e Desenvolvimento Econômico do Estado de São Paulo (SCTDE-SP), por solicitação do Codivar (Consórcio de Desenvolvimento Intermunicipal do Vale do Ribeira), com o objetivo de propor tecnologias economicamente viáveis para o aproveitamento dos resíduos da bananicultura, que se constitui na principal atividade econômica da região.

Uma característica do cultivo da banana é que após a colheita do cacho, a planta produtora tem o seu pseudocaule ("tronco") cortado, já que não voltará a dar frutos, para favorecer o desenvolvimento de um novo broto da planta. Esse procedimento provoca grande acúmulo de matéria vegetal (folhas, pseudocaule e engaço). Entre as alternativas estudadas para utilização desses "resíduos", a produção de artesanato baseou-se: a. na busca de sustentabilidade, considerando-se o aproveitamento de um resíduo como recurso local anteriormente não utilizado;

b. no resgate de técnicas artesanais comumente usadas entre a população alvo, viabilizando uma solução compatível com a prática cotidiana e o modo de vida local;

c. no desenvolvimento de uma atividade como fonte de renda, que pudesse ser praticada de forma complementar à agricultura de subsistência, viabilizando-a.

Além disso, o artesanato não requer pré-qualificação para a aprendizagem, envolve baixo custo para implantação e apresenta apelo comercial, principalmente quando atividade vinculada ao turismo, que vem sendo incrementado na região.

O Projeto Aproveitamento de Resíduos da Agroindústria da Banana do Vale do Ribeira, SP, pretendeu abordar a questão dos resíduos na perspectiva da sustentabilidade. Sem entrar no mérito das inúmeras discussões que tal conceito tem suscitado, parte-se aqui do princípio de que houve um esgotamento do modelo vigente na inter-relação homem-ambiente, sendo necessário redirecionar o projeto societário para a busca de um equilíbrio entre desenvolvimento econômico e preservação ambiental. Não se trata de obedecer a uma racionalidade ecológica dentro das engrenagens dos ciclos econômicos, em consonância à racionalidade tecnológica e à globalização do mercado, mas de buscar novos rumos, através de uma profunda reflexão teórica.

Nesse contexto, altera-se a relação entre cultura e sociedade, entre as diferentes significações sociais e os diversos potenciais da natureza. Uma ação voltada à sustentabilidade depende, assim, de uma intervenção participativa, tornando os seres humanos do local copartícipes do processo. Há que fortalecer a capacidade local de inovação; aliando e adaptando o acervo de conhecimentos e saberes do meio; acumulados na sua experiência histórica, às tecnologias externas, através de experimentação (LEFF, 2000).

As técnicas artesanais foram inicialmente desenvolvidas em laboratório, a partir da seleção e aprimoramento de um processo de coleta, limpeza e tratamento da matéria-prima. Através de contato prévio com artesãos e profissionais da região considerada, realizou-se um resgate de técnicas artesanais utilizadas com outras fibras e adaptações às características 
do material estudado. Foram então feitos testes na produção de artigos como esteiras, cortinas, assentos de cadeiras, sandálias, bolsas e outros objetos de uso doméstico e pessoal, além da produção artesanal de papéis especiais de diferentes texturas e colorações peculiares. Desta forma, foi possível verificar a viabilidade técnica da utilização da fibra de bananeira na composição de produtos artesanais e de decoração, desenvolvendo ampla gama de produtos.

Após se estabelecer um processo de produção de peças artesanais compatíveis com o material, iniciou-se a etapa de capacitação das novas técnicas nas comunidades alvo.

Buscou-se a divulgação do trabalho, por meio de visitas e comunicações pessoais com as Secretarias de Cultura e Assistência Social dos Municípios. Também foram realizadas exposições e participações em seminários na região. A partir desses contatos, foi possível a realização dos primeiros cursos de treinamento, em parceria com as prefeituras municipais. Os mesmos tinham por objetivo formar possíveis agentes multiplicadores constituídos por artesãos, professores ou funcionários qualificados e indicados por essas instituições.

Embora possa ser realizada uma avaliação positiva sobre esses cursos, no sentido de aprendizagem das pessoas envolvidas, o impacto foi reduzido. A avaliação posterior permitiu a identificação de alguns fatores que podem ser apontados como responsáveis: as pessoas treinadas já possuíam outra atividade remunerada, não assumindo as novas técnicas como base de seu sustento; por outro lado, não houve uma programação de continuidade dos treinamentos.

Assim, das comunidades treinadas nessa primeira fase, poucas deram prosseguimento a suas atividades. Duas foram exceções: os municípios de Miracatu e Itariri constituíram núcleos de produção, com apoio das prefeituras locais e posterior treinamento para aperfeiçoamento das técnicas; atualmente esses grupos estão produzindo cestarias, trançados e papel artesanal com características especiais.

Entretanto, a realização desses primeiros cursos propiciou a divulgação do trabalho do Projeto e o contato com outras instituições já atuantes na região do Vale, com novas oportunidades de cursos em outras localidades. Destaca-se aqui a participação da
Sutaco (Superintendência do Trabalho Artesanal de Comunidades, órgão Estatal), no patrocínio de alguns cursos e a interferência da Fundação Florestal, com o apoio da Fundação Palmares, entre outras.

O Instituto de Terras do Estado de São Paulo (INTESP) também propiciou apoio, assim como o Instituto Florestal, na unidade Caverna do Diabo, do Parque Estadual de Jacupiranga. Cabe destacar que esse apoio recebido do poder público, por meio desses diversos órgãos, não foi espontâneo, mas obtido a partir de contatos e reuniões solicitados pela coordenação do Projeto.

Os novos cursos realizados tiveram a característica de serem requisitados diretamente pelas comunidades locais e assim, de envolver a ação participativa das mesmas, o que contribuiu para o aumento de motivação e maior êxito nos treinamentos e posterior continuidade das atividades artesanais.

A equipe assumiu o compromisso de acompanhamento e solução, na medida do possível, dos problemas ocorridos na continuidade dos trabalhos realizados após o treinamento. Esse tipo de artesanato, assim como qualquer outro, para ser uma atividade rentável ou que remunere dignamente o artesão, necessita treinamento intensivo e rigoroso controle de qualidade dos produtos. Além disso, constatou-se ser necessária a iniciativa de lideranças locais para a organização da produção e busca de mercados formais, em pontos de venda para turismo ou lojas destinadas a um segmento social que se disponha a pagar pela exclusividade da peça. Foi nesse sentido que se procurou direcionar os trabalhos.

Ao todo, foram realizados 29 cursos na região, entre aqueles de treinamento e os de aperfeiçoamento, com acompanhamento das atividades por pesquisadores e técnicos do Projeto, em diferentes municípios.

Dentre os grupos treinados, cabe destaque especial às atividades nas comunidades rurais de remanescentes de quilombos, particularmente Ivaporunduva, André Lopes e Sapatu, do município de Eldorado. Seu envolvimento com o artesanato de bananeira foi imediato, verificando-se a produção de artigos que têm sido comercializados em feiras e exposições, com encomendas para o mercado interno e eventualmente para o exterior.

Como expansão das atividades do Projeto, foram oferecidos cursos em outras regiões do país: Macaé-RJ, Macapá-AP, Belém de Maria-PE, e Paranaguá-PR, entre 
outros, estabelecendo-se, portanto, novas parcerias. No total, foram mais de quarenta cursos oferecidos. Não há dados numéricos sobre as pessoas atingidas pelos agentes multiplicadores, embora se tenha notícia da sua existência, em praticamente, todo o território nacional. $\mathrm{Na}$ maioria dos casos, tem-se observado a continuidade das atividades artesanais com a fibra de bananeira. Contabilizados, os cursos oferecidos atingiram mais de 600 pessoas. Além das parcerias, a atividade tem recebido apoios de diferentes ordens, de diferentes instituições, seja através de doações de equipamentos e materiais necessários para confeccionar os produtos artesanais, (linhas, urdideiras, teares), em infraestrutura para o trabalho coletivo dos artesãos, como as sedes financiadas pelo governo do Estado de São Paulo, através do ITESP), em Sapatu e André Lopes e pelo Instituto Sócio-Ambiental ${ }^{\text {I }}$ (ISA) em Ivaporunduva; ou logístico, para comercialização dos produtos. Mais recentemente, o SEBRAE tem acompanhado o trabalho de forma definitiva em vários estados brasileiros.

\section{O PROJETO E A UNIVERSIDADE}

O trabalho que vem sendo desenvolvido proporcionou a vivência de questões fundamentais que se colocam para a academia quando se trata da geração de conhecimento científico com fins educativos, ou seja, visando a sua disponibilização para a promoção de cidadania. Nessa perspectiva, pode-se discutir a construção de uma universidade voltada para integração de pesquisas que aproximem a sociedade do limites acadêmicos, num processo amplo de inclusão social.

No atual modelo de universidade, epistemológico e ideológico, a pesquisa, a formação e a prática constituem três polos separados, em que os pesquisadores produzem conhecimento que são transmitidos durante a formação do aluno e depois aplicados na prática. Segundo Tardif (2000), de modo geral, os pesquisadores têm interesse em abandonar a esfera da formação e não investir tempo nos espaços de prática: antes de tudo escrevem e falam para seus pares, conse-

I Atualmente o ISA está desenvolvendo um projeto em parceria com a ESALQ/USP, e financiado pela FAPESP, atualmente, em comunidades quilombolas do município de Eldorado, SP. guem financiamentos e formam outros pesquisadores, constituindo um segmento isolado.

A experiência ora tratada permitiu um trabalho integrado, onde as questões de interdisciplinaridade na pesquisa e transversalidade na ação proporcionaram a prática da cidadania aliada à aprendizagem.

O desenvolvimento do Projeto só foi possível, a partir de uma ação interdisciplinar, tornando necessária a integração de diferentes áreas do conhecimento: biológica (envolvendo conceitos de estrutura e anatomia vegetal, microbiologia), exata e tecnológica (com ensaios físicos e químicos e adequação de equipamentos), ciências humanas (com o estudo da cultura das comunidades, dinâmicas de grupo, organização social, política, educação, economia e administração). O envolvimento de docentes e profissionais das diferentes áreas exigiu um exercício constante de trocas e experiências em que o diálogo era obstruído pela ausência de um discurso e de referências comuns e pelo uso de termos técnicos característicos a cada universo teórico em particular. Esses obstáculos tiveram que ser superados, num processo que se revelou profícuo e enriquecedor.

Por outro lado, a experiência permitiu aos alunos a aplicação prática dos temas que estudam e a percepção do papel do sujeito do conhecimento na sua produção, superando a dicotomia entre ambos. Por essa mesma via, abriu espaço para a inclusão de saberes extracientíficos, possibilitando a referência a sistemas de significados construídos na realidade prática.

No campo educacional, a interdisciplinaridade não é uma questão de método ou de técnica didática, mas uma necessidade. É algo que se torna imperativo, pois a produção do conhecimento e a prática docente de transmissão do conhecimento são constituídas nas e pelas relações sociais (FRIGOTTO, I995).

$\mathrm{Na}$ organização do processo pedagógico, a interdisciplinaridade tende a superar a fragmentação positivista da realidade e a divisão arbitrária das disciplinas quem vêm sendo observadas ao longo do desenvolvimento científico produzido na academia.

As populações com as quais houve interação, além de beneficiárias de uma técnica artesanal, trouxeram importantes questionamentos sobre a realidade social e econômica.

Sob a ótica da academia, é possível assumir que para as mesmas, com a adoção dessas técnicas, houve a possibilidade de obtenção de renda, aumento de autoestima e valorização da condição feminina, pela 
prática de atividade produtiva e rentável, além de incremento da integração social a partir dessa atividade. Entretanto, este tema por si só, demanda investigação mais profunda, ainda a ser realizada e que envolve questões amplas relacionadas à prática da interdisciplinaridade adotada durante as pesquisas acadêmicas que vêm proporcionando a execução do Projeto.

É nesse sentido, que projetos como o ora relatado têm papel primordial na aproximação dos conhecimentos adquiridos por meio das "experiências sociais" conforme expressão de Santos (2004), com os conhecimentos produzidos na academia; contribuindo assim, para um diálogo de saberes, que tende a enriquecer não só os conhecimentos locais, como também o conhecimento científico.

A interlocução desses conhecimentos não só contribui para construção de uma universidade mais aberta, como se aliam no debate de temas como pluralidade cultural, meio ambiente, cidadania, e na busca de alternativas para questões urgentes para as quais o conhecimento produzido no âmbito acadêmico ainda não fornece respostas.

A fecundidade que começa a se abrir entre o conhecimento científico e os saberes locais pode ser observada na execução do Projeto. Esta exigiu um diálogo crítico e criativo com a realidade e constante confronto da teoria com a questão prática; exigiu a busca da exata medida entre conhecimento técnico-científico, em que se baseou a pesquisa para o desenvolvimento artesanal, e a sua adequação às populações-alvo, dentro das condições de vida em que esta se mantém.

Assim, houve uma necessária aproximação do saber acadêmico, produzido com o rigor da racionalidade instrumental, à prática cotidiana, de valores e técnicas milenares. Se tal procedimento veio trazer um grau de indeterminação para o trabalho, no sentido de percorrer caminhos pouco usuais na academia, acabou por determinar o delineamento do foco central de todas as atividades e um processo de descobertas altamente satisfatório, tanto no campo do conhecimento quanto com relação ao processo ensino-aprendizagem.

O conhecimento procedente da pesquisa empírica baseada em diferentes marcos conceituais, acrescido do saber proveniente da análise da própria prática pelos artesãos, constituiu-se em importante fonte de construção do conhecimento para o ensino.

Vale ressaltar que o desenvolvimento do Projeto em tais moldes despertou um interesse por parte dos alunos, seja através de estágios supervisionados, participação em oficinas ou visitas às comunidades do Vale. Foram vários os pontos de identificação percebidos: a atualidade do tema, pela abordagem da questão ambiental e de sustentabilidade, a oportunidade de criar e transformar, com as próprias mãos, um resíduo em um artigo útil através da atividade artesanal e principalmente a possibilidade de contato com populações e a troca de experiências. Com a possibilidade de integrar o processo, tanto de construção do conhecimento, como de torná-lo acessível à população local, ficou evidente a importância da pesquisa como essencial à formação acadêmica, integrando ensino e extensão (SANTOS, 2003).

Por outro lado, o envolvimento destes no Projeto trouxe motivação adicional aos docentes e pesquisadores e tornou possível o desenvolvimento de novas dimensões, ampliando as estratégias de ação: estabeleceu-se uma relação de cumplicidade com propósitos de educação voltados para a cidadania e o ambiente. $\mathrm{O}$ estímulo da coresponsabilidade e o espírito cooperativo também foram deflagrados neste processo, criando condições para o diálogo, percepção de direitos e deveres. A intervenção na realidade entrou como importante ferramenta para o fortalecimento da cidadania e da postura crítica, sem a qual não é possível empreender a educação emancipatória.

Do ponto de vista da universidade, este trabalho tornou possível não só a construção de conhecimentos técnicos, mas também a ampliação da participação dos alunos em processos decisivos da comunidade e a busca de soluções para problemas reais de melhoria da qualidade de vida das populações envolvidas. Estimulou e apoiou a participação crítica dos alunos na gestão de seus espaços, na melhoria da qualidade de vida e também incrementou os sentimentos dos mesmos, como agentes multiplicadores, em relação à coresponsabilidade na solução de problemas socioambientais.

Por todos esses motivos, esse projeto proporcionou uma práxis que responde às críticas à universidade, sintetizadas por Santos (2003), expressas nas dicotomias alta cultura e cultura popular; educação e trabalho; teoria e prática; universidade e produtividade; universidade e comunidade. Particularmente, responde à crítica de que a universidade não está comprometida com os problemas nacionais - ou mesmo os 
problemas regionais ou locais da comunidade imediatamente envolvente, como a necessidade de educação de adultos e de formação profissional.

\section{REFERÊNCIAS BIBLIOGRÁFICAS}

FRIGOTTO, G. A interdisciplinaridade como necessidade e como problema nas ciências sociais. In: JANTSCH, A. P. e BIANCHETTI, L., orgs. Interdisciplinaridade: para além da filosofia do sujeito. Petrópolis: Vozes, I995.

LEFF, E. Tiempo de Sustentabilidad. Ambiente e Sociedade. Campinas, n. 6/7, p. 5-15, jan./dez., 2000.

SANTOS, B. S. Pela mão de Alice: o social e político na pós-modernidade. 9. ed. São Paulo: Cortez, 2003.

SANTOS, B. S. Para uma sociologia das ausências e uma sociologia das emergências. In: SANTOS. B. S., org. Conhecimento prudente para uma vida decente: um discurso sobre as ciências revidado. São Paulo: Cortez, 2004.

TARDIF, M. Saberes profissionais dos professores e conhecimentos universitários. Revista Brasileira de Educação, n. I3, p. 5-24, 2000. 